\title{
Athenaeus and the Control
}

\author{
Michael Witty
}

Very early experiments described in ancient literature usually have no detailed explanation of the methods used let alone the explicit Control expected by modern scientists for comparison with Treatments. Athenaeus describes a rarely recorded exception in The Deipnosophistae which has been briefly noted in scientific literature but not sufficiently contextualized. The experiment described has one treatment, a control and Athenaeus cites the desirability of replication, making this passage read like a modern text rather than an ancient one. Because technical processes were invented in ancient times I assume that experiments were also practiced, even though they are not described in ancient literature. This passage in Athenaeus exemplifies, by rare contrast, the general lack of description for ancient scientific methods. This lack may be because the ancient practitioners of technical processes did not have the reason modern scientists use for disclosure of all methods and results. Moderns achieve monetization that is protected by Intellectual Property Law or by acquisition of authority followed by salaried teaching in the academy. Ancient experimenters protected their discoveries by secrecy and maintained monopolies by concealment, an inconvenience for modern scholars. The form of ancient literature is important for this subject: it is not like modern scientific literature. When the ancients mention scientific subjects in writing it is in the form of literary discourse and debate where the aim is cerebral. There is no description of technical details where the aim is to allow replication of the experiment. Comfortable logic not experiment is described and intellectual improvement was usually the aim of ancient literature, rather than practical outcomes. The only reason we have knowledge of ancient practitioners of something similar to modern scientific methods from literature is that their kind of technical antics were briefly mentioned by ancient authors, because of their surprising and amusing nature.

An experiment is like a question for reality and extremely important in epistemology related to many complex natural phenomena. It is useful to compare the results of an experimental treatment with what would have happened if we did not intervene in nature. In Natural Experiments we can make a comparison with what we remember from the past, however memory is imperfect. It is much better to have two treatments where one shows us what happened when we do something and a second simultaneous treatment reminds us of what happens when we do not do that thing. Simultaneity is important because then we can hold both treatments in our hands and compare them directly and in detail, not imagine what could have happened through the frail filter of memory. This second treatment has come to be called the Control. 
The Control is usually considered to be a modern tool originating in the enlightenment and perfected in the early $20^{\text {th }}$ century, as can be seen from definitions of the word recorded in two dictionaries, the first from Johnson:

Control. 1. A Register or account kept by another officer, that each may be examined by the other. 2. Check; restraint. Waller. 3. Power; authority; superintendence. Shakesp.

To Control. 1. To keep under check by a counter reckoning. 2 To govern; to restrain; to subject. Prior. 3. To overpower; to confute. Bacon. (Johnson 1768, all definitions of Control) ${ }^{1}$

Confusing or irrelevant symbols and abbreviations have been omitted and the "long $\mathrm{s}$ " has been translated to " $\mathrm{s}$ ". The lack of a special scientific definition is despite the fact that Johnson was a keen amateur scientist:

Dr. Johnson was always exceeding fond of chemistry; and we made up a sort of laboratory at Streatham one summer, and diverted ourselves with drawing essences and colouring liquors. But the danger Mr. Thrale found his friend in one day when I [Mrs Thrale] was driven to London, and he had got the children and servants round him to see some experiments performed, put an end to all our entertainment; so well was the master of the house persuaded, that his [Johnson's] short sight would have been his destruction in a moment, by bringing him close to a fierce and violent flame $<\ldots>$ Future experiments in chemistry $<\ldots>$ were [considered] too dangerous, and Mr Thrale insisted that we should do no more towards finding the philosopher's stone. Mr Johnson's amusements were thus reduced to the pleasures of conversation $<\ldots>$. (Piozzi 1822: $190-191$ )

The amateurs were gradually overtaken by professionals in the nineteenth century and science became less a common hobby and more a serious subject of philosophy with specialized jargon, such as the "Method of Difference":

If an instance in which the phenomenon under investigation occurs, and an instance in which it does not occur, have every circumstance save one in common, that one occurring only in the former; the circumstance in which alone the two instances differ, is the effect, or cause, or an indispensable part of the cause, of the phenomenon. (Mill 1843) ${ }^{2}$

It is interesting to compare Johnson's to the relevant modern definition ${ }^{3}$ where we can see that by 1875 the scientific definition of Control had become well known enough to attract the attention of lexicographers.

\footnotetext{
${ }^{1}$ Johnson, S. (1768).

${ }^{2}$ Mill, J. S. (1843: 455).

${ }^{3}$ Simpson, J. A and Weiner, E. S. C. (1989: 852).
} 
[3 b.] In mod. scientific use: A standard of comparison used to check the inferences deduced from an experiment, by application of the 'Method of Difference'. Often attrib. as in control-experiment, a test experiment devised with this end in view. 1875 Darwin Insectiv. Pl. xvii. 413 Four bladders were first tried as a control experiment. (Simpson and Weiner 1989)

Between Johnson and Darwin, we assume the modern empirical scientific definition of the Control was invented, to cope with the new profession of Public Scientist. Johnson's dictionary does have the idea of a comparison in the definition of Control, making it understandable that the word was adopted by professional scientists later. In reality only the definition, not the concept of the Control was invented after Johnson. Technically oriented people, rather than enthusiastic amateurs, had the idea of a Control many centuries earlier. The word Control is used as a modern description of a long standing informal epistemology rather than an invention.

Athenaeus' great work Deipnosophistae (The Sophisticated Diners) is an abundant source of knowledge of Greek and Symposium language, culture and science. It shows the amazing persistence of Greek culture past the early period of Hellenic supremacy into the Roman period of Hellenic subjugation and even features relevant to the modern age, as described below. Athenaeus of Naucratis (late 2nd to early 3rd century AD) is read and appreciated by many classicists and antiquarians but only a very few scientific scholars. Athenaeus wrote long imaginary dialogues between members of a club of guests at a learned banqueter's dinner, a symposium, regarding recipes, dolphins, flute girls, who pays the expenses for a poor diner and when to leave a party, among many other things. These men also occasionally discussed matters whose value can best be recognized by the few scientists that read and fully appreciate passages such as the following.

$<\ldots>$ When the citron is eaten before any food, dry or liquid, it is an antidote to every poisonous ingredient; I learned this from a townsman of mine who was entrusted with the governorship of Egypt. He had sentenced some convicted criminals to be the prey of wild beasts, and they were to be thrown among the creatures called asps. As they were entering the theatre assigned for the punishment of the robbers, a peddler-woman in the street gave them in pity some of the citron which she was holding in both hands and which she was eating. They took it and ate, and when, after a short time, they were thrown among those cruel and monstrous creatures, the asps, they received no injury when bitten. Perplexity seized the magistrate, and finally he questioned the soldier who guarded them to see whether they had eaten or drunk anything; when he learned that the citron had been given them, he ordered next day that a piece of citron should be given, exactly as before, to one convict, but not to the other, and the one who ate suffered no injury when bitten by the reptiles, but the other died the moment he was struck. And so, since the same result has been 
attested in many instances, the citron has been proved to be an antidote to every poison. (Gulick 1927) ${ }^{4}$

A great deal has been written about ancient experiments ${ }^{5}$ and many examples of very early Natural Experiments ${ }^{6}$ which have no explicit, contrived Control have been described. What is different in the example above is the presence of a separate treatment where it is assumed there is only one difference between it and the treatment of interest and we call that separate treatment the Control in modern times. This passage has been very briefly noted by modern authors ${ }^{7}$, but not fully appreciated. It is unique because there is enough information to repeat the experiment, a significant criterion for modern papers describing controlled experiments.

Athenaeus is one of several ancients who had something to record about the citron (Citrus medica) and medicine, principally Pliny $^{8}$ (23 AD to 79 AD) who describes this plant and Theophrastus ${ }^{9}$ (c. 371 to c. 287 BC) who asserts that citron juice in wine is a good antidote to poison when used as an emetic. Compared to Theophrastus and Pliny, Athenaeus is medically confused regarding the citron. However, this particular part of Athenaeus' text is still significant to the modern age because it shows a thinking method remarkably similar to the predominant practice of modern science, where use of a control is a practice which is very effective at finding the particular causes of phenomena and rejecting co-correlates or at least falsifying confounding co-correlates. ${ }^{10}$ It allows precise comparison between the results of an experimental treatment and what would have happened in the absence of that treatment, giving an indication of causal factors. ${ }^{11}$ Early scientists often compared the results of an experiment with experience gained in the past or in other places; natural experiments. This is unlike an explicit control which allows easy

\footnotetext{
${ }^{4}$ Gulick, C (1927), especially 3.84.d-f and 12.521.c-d.

${ }^{5}$ Olson, S. D. (2010); Cuomo, S. (2007).

${ }^{6}$ Taub, L. (2017).

${ }^{7}$ Krauth, J. (2000); Prioreschi, P. (1988); Thorndike, L. (1923: I 37-334).

${ }^{8}$ Rackham (1965: IV, XII.VII.15).

${ }^{9}$ Hort (1916: 4.4.2-3).

${ }^{10}$ Popper (1959).

${ }^{11}$ Boring (1954); Bos (2007).
} 
comparison with the normal state of affairs for a system. It is rare to find any mention of a controlled experiment before the modern age. In the passage above Athenaeus implies an idea regarding the citron, then a controlled experiment to see if the idea has merit or not, depending on comparison between the control prisoner and the experimental prisoner; to see if he lived or died. Repetition of experiments is also cited making this read like a very modern procedure, completely unexpected in an author as early as Athenaeus.

In the history of science, we suppose that Aristotle observed natural phenomena and conducted dissections $^{12}$ but it was only much later that self-conscious experiments, or at least discussions of them, are known, let alone explicitly controlled experiments where comparisons between treatments and controls are contrived. Tests and experiments such as detecting poisonous gasses by lowering a lighted lamp into a well as it is being dug are, of course, part of an early tradition including Pliny ${ }^{13}$, Vitruvius ${ }^{14}$ (c. $80-70$ BC to c. 15 BC) and Palladius ${ }^{15}$ (late 4 th to early 5th century AD), but they have no explicit control and the comparison being made is between the observation of the day and previous experience. Many like to cite medievals like Albert of Cologne ${ }^{16}$ (c. 1200 to 1280) or Roger Bacon ${ }^{17}$ (c. $1219 / 20$ to c. 1292) as the earliest experimenters of the present tradition rather than the more conventionally cited Galileo ${ }^{18}$ (1564 to 1642 ), or James Lind ${ }^{19}$ (1716 to 1794). Some or all of these men may have carried out experiments and in addition recorded their ideas in writing, though this is not clear in some of my cited cases. Precisely controlled early experiments are hard to find and it is only from 1648 and onwards that we begin to read of explicitly defined experiments with controls from scientists like Pascal (1623 to 1662), Faraday (1791 to 1867) and Tyndall (1820 to 1893) where Pascal's experiment regarding the weight of the atmosphere conducted in 1648 is a great example of an experiment with a

\footnotetext{
${ }^{12}$ Bos AP (2007).

${ }^{13}$ Op. cit. XXXI.XXVIII.15.

${ }^{14}$ Granger F (1970). Vitruvius, De Architectura VIII.VI.12-13.

${ }^{15}$ Fitch JG (2013). Palladius, Opus Agriculturae IX.9.

${ }^{16}$ Banas (2006).

${ }^{17}$ Clegg (2003).

${ }^{18}$ Drake (1973); Naylor (1976).

${ }^{19}$ Tröhler (2005).
} 
control and is described in detail in Boring. ${ }^{20}$ The idea of a controlled experiment in Athenaeus is much older than all of this, more than 1000 years older than what we recognize as the beginnings of the modern age of science. Most assume that all the ancient technologists ${ }^{21}$ and medievals were capable of was natural experiments and observational studies. This is not meant to excessively disparage natural experiments. Many interesting works of important scientists are natural experiments; famous examples being Snow's analysis of the 1854 Broad Street cholera outbreak ${ }^{22}$ and Semmelweis' analysis of Puerperal Fever epidemiology. ${ }^{23}$ Natural experiments are limited but the method remains useful to this day and sometimes it is the best possible method. ${ }^{24}$ Perhaps the words of Corcoran add clarity regarding the ancients:

"His [Seneca's] age evaluated theories by the arguments of analogy. To test a theory by controlled experiment was not a standard reflex and it would be inappropriate to expect it. His contribution, as he and his age saw it, was to present to the reader what had been learned (i.e. the theories) about phenomena, to demonstrate (sometimes, but not always) by analogy which explanations were seemingly wrong or foolish, to indicate (again sometimes but not always) which theory or theories he preferred (and he could accept more than one as an explanation), and to make moral observations on something suggested by the topic. Also, the study itself of what had been learned about natural phenomena was felt by Seneca to provide moral improvement”. (Corcoran 1971: xiv)

All of this without Seneca's having to leave the comfort of his kline. The long period when details of experiments like explicit controls were not described by the literature of philosophers might possibly be because controls were never used. Alternatively, it may relate to the fact that the results of technical experimentation were often valuable intellectual properties and their monetization could usually only be protected by secrecy ${ }^{25}$, a common and obvious conclusion of many classicists ${ }^{26}$, including this example:

\footnotetext{
${ }^{20}$ Boring (1954).

${ }^{21}$ For example Athenaeus II.52.d-e.

${ }^{22}$ Snow (1855).

${ }^{23}$ Semmelweis (1861).

${ }^{24}$ Diamond (1983).

${ }^{25}$ Adolph (1927); see also materials cited within.

${ }^{26}$ Levey (1956); Venticinque (2010).
} 
Technical knowledge, including technical terminology, must have been, by and large, communicated and transmitted non-textually, that is, both orally and instrumentally $\langle\ldots\rangle$. Nontextual learning such as Datus [the engineer] possessed, especially if it implied skilled manipulation of instruments, must have required the existence of an actual, not simply a virtual [written], community of experts, probably hierarchically arranged, and identified by its sharing of knowledge, knowledge practices, and the values associated with them. (Cuomo 2011)

That this secrecy was important is revealed by the competition between ancient Roman guilds and the wishes of emperors as revealed in the correspondence of Pliny (61 to c. 113 $\mathrm{AD})$ and Trajan (53 to $117 \mathrm{AD})$.

[Epistula 33, Pliny to Trajan]. While I was visiting a distant part of the province a most desolating fire broke out at Nicomedia and destroyed a number of private houses and two public buildings, the almshouse and temple of Isis, although a road ran between them. The fire was allowed to spread farther than it need have done, first, owing to the violence of the wind, and, secondly, to the laziness of the inhabitants, it being generally agreed that they stood idly by without moving and merely watched the catastrophe. Moreover, there is not a single public fire-engine or bucket in the place, and not one solitary appliance for mastering an outbreak of fire. However, these will be provided in accordance with the orders I have already given. But, Sir, I would have you consider whether you think a guild of firemen, of about 150 men, should be instituted. I will take care that no one who is not a genuine fireman should be admitted, and that the guild should not misapply the charter granted to it, and there would be no difficulty in keeping an eye on so small a body.

[Epistula 34, Trajan to Pliny]. You have conceived the idea that a guild of firemen might be formed in Nicomedia on the model of various others already existing. But it is to be remembered that your province of Bithynia, and especially city states like Nicomedia, are the prey of factions. Whatever name we may give to those who form an association, and whatever the reason of the association may be, they will soon degenerate into secret societies. It is better policy to provide appliances for mastering conflagrations and encourage property owners to make use of them, and, if occasion demands, press the crowd which collects into the same service. (Pliny X 33 and 34; Fort 1881; Firth 1900).

This secrecy of technical ancients was maintained partly because of upper class distain $^{27}$ and partly to preserve the secrets of professions ${ }^{28}$, similar to the well known practices of medieval guilds. The law of the Sybarites related to public celebrations is an exception $^{29}$ which is relevant because of its exceptional rarity, originating in the public nature of catering.

$<\ldots>$ If any caterer or cook invented a dish of his own which was especially choice, it was his privilege that no one else but the inventor himself should adopt the use of it before the lapse of a

\footnotetext{
${ }^{27}$ Greene (2008).

${ }^{28}$ Cuomo (2011).

${ }^{29}$ Cichorius (1922); Frumkin (1945).
} 
year, in order that the first man to invent a dish might possess the right of manufacture during that period, so as to encourage others to excel in eager competition with similar inventions. (Athenaeus $12.521 \mathrm{c}-\mathrm{d})$

Plainly the status of cooks was higher in ancient Sybaris that it is today and their innovation was valued highly ${ }^{30}$, and in addition the inventor of the best dish could receive an honorific garland. ${ }^{31}$ We see in Athenaeus that the elaborate idea of an experiment with a control existed in his time, and this supports the notions of modern people that attempt to recreate ancient technology $\mathrm{y}^{32}$, that sophisticated scientific practice existed too. The reason we do not know more about ancient technology is that the practitioners were only interested in practical outcomes. Technical scientists interested in going to the modern metaphorical agora and monetizing their ideas by increasing their public intellectual status then teaching, did not exist. Only a few ancient philosophers did that, not ancient technologists. The ancient technical scientists protected their ideas with secrecy and monetized their ideas by preserving a private and secretive monopoly, perhaps some of them using elaborate methods like controls and duplicate treatments. This made them appear curious, unusual and alchemical - people that were interesting and had the allure of magic. ${ }^{33}$ This is despite the fact that they must also have seemed like lower class scum to the Deipnosophistae, like the peddler woman (above) or Fullers. ${ }^{34}$ Athenaeus' text represents an exciting example of what the early secretive technical class did, which was interesting enough for the exulted imaginary guests of Athenaeus to gossip about at their learned dinners.

Michael Witty Florida SouthWestern State College

\footnotetext{
${ }^{30}$ Witty (2018).

${ }^{31}$ Athenaeus XII 519 e.

32 Witty (2016).

33 Thorndike (1923).

${ }^{34}$ McClure (2003).
} 


\section{References}

Adolph, E. F. (1927) The Growth of Experimentation in the Early Sciences. The Scientific Monthly 25(1): 19-24.

Banas, J. (2006) Albert the Great as a scientist. Organon F 13(1): 16-31.

Boring, E. G. (1954) The nature and history of experimental control. The American Journal of Psychology 67(4): 573-589.

Bos, A. P. (2007) Aristotle on Dissection of Plants and Animals and his Concept of the Instrumental Soul-Body. Ancient Philosophy 27(1): 95-106.

Cichorius, C. (1922) Ein Patentgesetz aus dem griechischen Altertum. Jahrbücher für Nationalökonomie und Statistik. Journal of Economics and Statistics 63(1): 46-48.

Clegg, B. (2003) Roger Bacon, the first Scientist. Carol and Graph: New York.

Corcoran, T. H. (1971) Naturales Quaestiones by Seneca. Loeb Classical Library: Harvard University Press, Cambridge, Massachusetts.

Cuomo, S. (2007) Technology and culture in Greek and Roman Antiquity. Cambridge University Press: Cambridge.

Cuomo, S. (2011) A Roman engineer's tales. The Journal of Roman Studies 101: 143-165.

Diamond, J. M. (1983) Ecology: laboratory, field and natural experiments. Nature 304 (5927): 586587.

Drake, S. (1973) Galileo's experimental confirmation of horizontal inertia: unpublished manuscripts (Galileo Gleanings XXII). Isis 64(3): 291-305.

Firth, J. B. (1900) Letters of Pliny the Younger, Book 10, Letters 33 and 34. http://www.attalus. org/old/pliny10a.html\#33 and http://www.attalus.org/old/pliny10a.html\#34. Downloaded 30/1/20.

Fitch, J. G. (2013) Palladius, Opus Agriculturae. Prospect Books.

Fort, G. F. (1881) The Early History and Antiquities of Freemasonry: As Connected with Ancient Norse Guilds, and the Oriental and Mediaval Building Fraternities. Bradley and Company, Philadelphia.

Frumkin, M. (1945) The Origin of Patents. Journal of the Patent Office Society 27(3): 143-149.

Granger, F. (1970) Vitruvius, De Architectura. Loeb Classical Library: Harvard University Press, Cambridge, Massachusetts.

Greene, K. (2008) Inventors, invention, and attitudes toward technology and innovation. The Oxford handbook of engineering and technology in the classical world, chapter 32. Oxford University Press: Oxford.

Gulick, C. (1927) Athenaeus: The Deipnosophists. Vol. 1. Loeb Classical Library: Harvard University Press, Cambridge, Massachusetts.

Hort, S. A. (1916) Enquiry into Plants, by Theophrastus. Loeb Classical Library: Harvard University Press, Cambridge, Massachusetts, 70 and 79.

Johnson, S. (1768) A Dictionary of the English Language. London, 3rd edition.

Krauth, J. (2000) Experimental Design, Volume 14. Elsevier Science. 
Levey, M. (1956) Babylonian chemistry: a study of Arabic and second millenium BC perfumery. Osiris 12: 376-389.

McClure, L. (2003) Subversive laughter: The sayings of courtesans in book 13 of Athenaeus' Deipnosophistae. American Journal of Philology 124(2): 259-294.

Mill, J. S. (1843) A System of Logic, Ratiocinative and Inductive: Being a Connected view of the Principles of Evidence, and the Methods of Scientific Investigation, Volume 1, Parker: London.

Naylor, R. (1976) Galileo: Real experiment and didactic demonstration. Isis 67(3): 398-419.

Olson, S. D. (2010) Athenaeus: The Learned Banqueters. Loeb Classical Library: Harvard University Press, Cambridge, Massachusetts.

Piozzi, H. L. (1822) Anecdotes of Samuel Johnson, LL.D. during the last Twenty Years of his Life. Allman: London.

Popper, K. (1959) The logic of Scientific Discovery. Basic Books: New York.

Prioreschi, P. (1988) Roman Medicine. Horatius Press: Omaha, Nebraska.

Rackham, H. (1965) Pliny, Natural History. Vol. IV. Loeb Classical Library: Harvard University Press, Cambridge, Massachusetts.

Semmelweis, I. P. (1861) Die Aetiologie, der Begriff und die Prophylaxis des Kind-bettfiebers. Pest, Wien and Leipzig: C. A. Hartleben. Translated by Frank P. Murphy in 1941.

Simpson, J. A. \& Weiner, E. S. C. (1989) The Oxford English Dictionary. Clarendon Press: Oxford, 2nd edition.

Snow, J. (1855) On the mode of communication of cholera. Second edition, John Churchill.

Taub, L. (2017) Science Writing in Greco-Roman Antiquity. Cambridge University Press: Cambridge.

Thorndike, L. (1923) History of Magic and Experimental Science. Columbia University Press: New York.

Tröhler, U. (2005) Lind and scurvy: 1747 to 1795. Journal of the Royal Society of Medicine 98(11): 519-522.

Venticinque, P. F. (2010) Family affairs: guild regulations and family relationships in Roman Egypt. Greek, Roman, and Byzantine Studies 50(2): 273-294.

Witty, M. (2016) Ancient Roman Urine Chemistry. Acta Archaeologica 87(1): 179-191.

Witty, M. (2018) Athenaeus describes the most ancient intellectual property. Prometheus 35(2): 137-143. 